with their feet upon the solid earth of the twentieth century, but with their heads in the mists of the middle ages." As to the old reply that education must be 'liberal', Mr. Moorfield was very clear : "Whilst we do not scorn to provide instruction in matters relating to the manual dexterity of the artizan, we emphasise the necessity for the deeper understanding which is provided in a complete technical course designed to meet the needs of those engaged in particular occupations. Such a course is a continuation of a liberal education and cannot in any sense be narrow. Contacts with other occupations are constantly being made, and the engineer begins to understand the miner and the miner the engineer, and the builder will make the acquaintance of both." "We stand for that kind of education which will enable human beings so completely to understand the forces of Nature that the fear of these things, which, in the past, has bred devil-worship, witchcraft, and superstitions in general, may be banished from their lives and cease to burden them with oppression." Further, technical education is " the very spearhead of the attack upon drudgery and want, the fundamental causes of such a large proportion of human unhappiness ".

Modern civilisation, however, involves something more than the development of engineering and chemistry and all those departments which come so easily under a scientific heading. They all aim at the successful production which technical efficiency can give. But technical efficiency towards production is not enough. If products be not adequately distributed, their value disappears; and it is in distribution that we find our most pressing problems. Upon the edifice of scientific production we have to impose an equally scientific scheme of distribution. At present the latter is chaotic, and the commercial sides of our great technical institutions are developing schemes of education to remedy the defect. The recent crisis brought to the forefront problems which seem to be baffling even to the expert. There are gluts of wheat, rubber, coffee, tea, iron, copper, tin, and even diamonds. Gold lies uselessly hoarded in the coffers of two or three of the great nations of the earth. "With plenty in the world, men suffer privation and want." It was in this connexion that Mr. Moorfield called for closer liaison between commercial teachers and the general body of technical teachers. Already their function has been laid down in no narrow sense by the Committee on Education for Salesmanship : "Salesmanship as we understand it is a prime function of direction and supreme management. . . . It embraces the study of the fundamental principles of commerce . . . it is therefore education for commerce on its creative, organising, and executive sides."

Among the resolutions dealt with by the Conference was one urging the closer co-operation of education and industry by means of the formation of a national co-ordinating committee composed of representatives of industry, commerce, educational administration, and technical teachers. Such a committee would be invaluable as a clearing-house for ideas and proposals made by similarly constituted committees which have been formed to act regionally. Another resolution urged the remission of part of the period of apprentice. ship for pupils who have followed a full-time course in a technical institution, the extension of opportunity for all entrants into industry to become skilled workers, and the provision of part-time day courses for ap. prentices and other adolescent workers.

The Conference was officially welcomed by the Lord Mayor of Cardiff and Councillor J. Hellyer, deputy chairman of the Education Committee. An exhibition of books and apparatus was held in the Cardiff Technical College. At the annual dinner of the Association on Whit Monday, Prof. George Knox, who has done so much for mining education in South Wales, directed attention to the essentials to industrial success. In addition to capital, raw material, and machinery, suitable personnel to advise upon, organise, and manage these essentials is an absolute necessity. How far, he asked pertinently, has the lack of attention to this matter of personnel contributed to the present position of secondary industries in the South Wales area?

\title{
White Dwarf Stars
}

THE Halley Lecture delivered at the University of Oxford by Prof. E. A. Milne on May 19 was on the subject of the "White Dwarf Stars". He said that the discovery by Halley of the proper motion of some of the fixed stars led to a remarkable succession of researches in pure astronomy, in modern physics, and in cosmogony generally. The proper motion of one of Halley's stars, Sirius, was found by Bessel not to be uniform, but to contain a periodic element of about fifty years. This led him to suggest that Sirius was in reality double, consisting of a pair of stars, one much fainter than the other. In 1862 a faint star, Sirius $B$, was actually seen by Alvan Clark close to the place that had been theoretically assigned to the supposed companion. In 1915, W. S. Adams at Mount Wilson Observatory succeeded in obtaining a photograph of the spectrum of Sirius $B$, which led to the unexpected conclusion that the density of Sirius $B$ was of the order of one ton to the cubic inch. It was shown by Eddington that this surprising density was not physically improbable, and further, that in the light of Einstein's general theory of relativity, the relative displacement of the lines of the spectrum of Sirius $A$ and Sirius $B$ could be estimated. The measurement when actually carried out by Adams in 1925 gave a result so near that of Eddington's estim- ate that the computed small radius and high density of Sirius $B$ may now be accepted with confidence. A few other stars besides Sirius $B$ are known in which low luminosity and abnormal blueness are combined with high density; these are known as 'white dwarfs'. They are all within five parsecs of the sun, but there is no reason to suppose that this is an abnormal region of space. Consideration of the phenomenon of novaoutbursts and the study of the nuclei of planetary nebulæ lead to the conclusion that the list of dense objects can be largely extended. The physical state of matter at these high densities has been elucidated by R. H. Fowler in the light of the researches of Fermi and Dirac. The existence of white dwarf stars shows that it is possible for any gas to exist in either of two states or phases, the 'perfect' or the 'degenerate" phase; the dense state being identified with that of the second phase of a gas. It is suggested that, as foreshadowed by Bessel in regard to Tycho's nova of 1572 , the system of Sirius may owe its origin to the nova phenomenon of the original Sirius; two companions resulting, of which one re-expanded and the other remained dense. Bessel's anticipation of the interest of these phenomena in relation to our knowledge of the physical constitution of the universe has been amply justified by the course of events. 